\title{
Social vulnerability for public safety: A case study of Beijing, China
}

\author{
ZHANG Nan \& HUANG Hong* \\ Institute of Public Safety Research, Department of Engineering Physics, Tsinghua University, Beijing 100084, China
}

Received November 16, 2012; accepted January 4, 2013

\begin{abstract}
Vulnerability to hazards includes not only components of a physical nature, but also those arising from social factors. In developing measures for disaster prevention or emergency response for disaster relief of big cities, an analysis of social vulnerability is very necessary but quite difficult. In order to address the problem, using Beijing as an example, we established a social vulnerability index system including 26 factors and developed an improved analytic hierarchy process (AHP) method. The weight of each factor was evaluated using the improved AHP process that obviously increased the passing rate of consistency of the experts' questionnaire. The population, career, economy, infrastructure and social vulnerability distribution maps of Beijing were obtained. From them, it's easy to see the characteristics of various vulnerability distributions. Through sensitivity analysis, the influencing factors of each area were listed in order of importance. The approach are useful for assessing, reducing the social vulnerability of big cities in China.
\end{abstract}

social vulnerability, public safety, analytic hierarchy process, sensitivity analysis, Beijing

Citation: Zhang N, Huang H. Social vulnerability for public safety: A case study of Beijing, China. Chin Sci Bull, 2013, 58: 2387-2394, doi: 10.1007/s11434-013$5835-\mathrm{x}$

Public safety is threatened by numerous disasters and accidents which lead to tremendous losses including human life, damaged infrastructures and lifelines, collapsed buildings and houses, unstable society and other hazards. Generally, the losses vary geographically, over time and among different social groups. Researchers have gradually recognized that the vulnerability of a disaster acceptor is an important reason for the disaster occurring as well as for the difference in losses across different areas. Analyzing the vulnerability of a disaster acceptor so as to provide methods to reduce vulnerability is an effective way to increase the ability to prevent disaster, and an effective way to reduce loss. From this point of view, research into vulnerability is very important in the public safety science.

The degree to which populations are vulnerable to hazards is not only dependent upon the physical nature of the world, but also the social aspects. Social factors also play a significant role in determining vulnerability $[1,2]$. Therefore, the vulnerability to hazards includes two components:

*Corresponding author (email: hhong@tsinghua.edu.cn) physical vulnerability and social vulnerability. Considerable researches have focused on the physical vulnerability component, with the social vulnerability component being largely ignored. For example, during Hurricane Katrina, many of the poorer citizens of New Orleans could not evacuate for a lack of transportation [3]. It is estimated that some 250000 poor residents in New Orleans had no access to personal vehicles [4]. The evacuation plan only considered the evacuees who could access to vehicles and was a devastating failure for the socially vulnerable population that was unable to leave. These problems highlight the need to better integrate social science research concerning social vulnerability into emergency and risk management decision-making. In recent years, there has been some research into social vulnerability. Cutter et al. [5] established the Social Vulnerability Index (SOVI) to examine the spatial patterns of social vulnerability to natural hazards at the county level in the United States. Burton [6] incorporated social vulnerability into numerical hurricane impact modeling to improve loss prediction. Jose [7] constructed an index of social vulnerability to natural and technological hazards and to social 
risks in the central region of Portugal, for all the municipalities of the region. The social vulnerability index value based on mail delivery data for Orleans Parish was calculated [8]. Adger [9] illustrated the development of social vulnerability and noted that social vulnerability is related to economic factors. Fekete [10] obtained the social vulnerability index map and showed that social vulnerability is hard to validate. In China, relevant systematic research is still lacking [11-13].

As the capital of China, research into Beijing's social vulnerability should be given more attention. High population density and numerous important facilities lead to a significance of vulnerability analysis even though space is not very large. Analyzing the social vulnerability of all areas and doing relevant assessments focusing on Beijing's characteristics will contribute to implementing corresponding action on the social vulnerability situation for each area and to enable action according to circumstances. Thus when disaster is approaching, we can draw up a more efficient and comprehensive emergency plan to rescue those in need as soon as possible.

In this study, the social vulnerability index system based on an improved Analytic Hierarchy Process (AHP) method was established and the social vulnerability combining with the characteristics of 333 areas of Beijing were evaluated and analyzed. The main objective is to analyze the social vulnerability to hazards and the sensitivity of each influencing factors, to achieve risk prevention and mitigation and to elaborate the plan of effective risk response strategies in Beijing.

\section{Social vulnerability index}

\subsection{Concept of social vulnerability}

There is not an acceptable definition for social vulnerability which can satisfy the requirements of every research area. Adger [9] described social vulnerability to be the exposure of groups or individuals to stress as a result of social and environmental change, where stress refers to unexpected changes and disruption to livelihoods. Phillips et al. [3] showed that underlying each concept of social vulnerability is the recognition that some citizens face higher risk of injury, death, or property loss because of their social and economic circumstances and because mainstream society marginalizes their cultural frameworks or situational locations. Schmidtlein et al. [4] defined social vulnerability to be the likelihood of sustaining losses from some actual or potential hazardous event, as well as the ability to recover from those losses. In ecology, vulnerability expresses the extent of damage of ecosystem [14]. Brooks [15] stated that the definition of vulnerability which is proposed by IPCC (Intergovernmental Panel on Climate Change) is a function of the character, magnitude, and rate of climate variation to which a system is exposed, its sensitivity, and its adaptive capacity [16]. It is a degree to which the coupled humanenvironment systems or some part of it is likely to experience harm due to exposure to a hazard [17].

In this study, the concept defined by Cutter et al. [1] was used. Social vulnerability is described using the individual characteristics of people (age, race, health, income, type of dwelling unit, employment) [4], and is partially the product of social inequality. Social vulnerability is a potential for loss. Since losses vary geographically, over time, and among different social groups, social vulnerability also varies over time and space.

\subsection{Influencing factors and the social vulnerability index system}

Social vulnerability to hazards is influenced by a great number of factors, such as population density, occupation kind, infrastructure conditions and other relevant factors. Generally, social vulnerability is divided into two parts: human vulnerability and the ability to access resources [1]. In this study, we separate each part into direct and indirect parts. For human vulnerability, the direct part is called population vulnerability which includes human characteristics such as gender, ethnicity, marital status etc. The indirect part is called career vulnerability that includes the occupation of the citizen since we consider that different occupations would greatly affect a person's vulnerability. For resources, Chakraborty et al. [18] calculated the social vulnerability on the basis of differential access to resources. In this research, the direct part is called economic vulnerability which includes Engel coefficient, per capita income, etc. The percentage of old houses, number of fire stations per square kilometer and so on is called infrastructure vulnerability and is indirectly linked with resources. Therefore social vulnerability can be divided into four parts: population vulnerability, career vulnerability, economic vulnerability and infrastructure vulnerability. Also 26 secondary indices (including population density, percent of ethnic minorities, percent of illiterate, ratio of unemployment, percent of social welfare, per capita income etc.) were obtained according to the characteristics of Beijing and some relevant studies [5,6,19,20]. Details are shown in Figure 1.

\section{Study area and data}

\subsection{Application in Beijing}

As the capital of China, Beijing's public safety is of great importance. Beijing has high building and population densities, a complicated component of people (including various residence characteristics, ethnicities, education levels etc.), which leads to the complexity of research into social vulnerability. In this study, the social vulnerability of Beijing is analyzed using the social vulnerability index system developed above. 


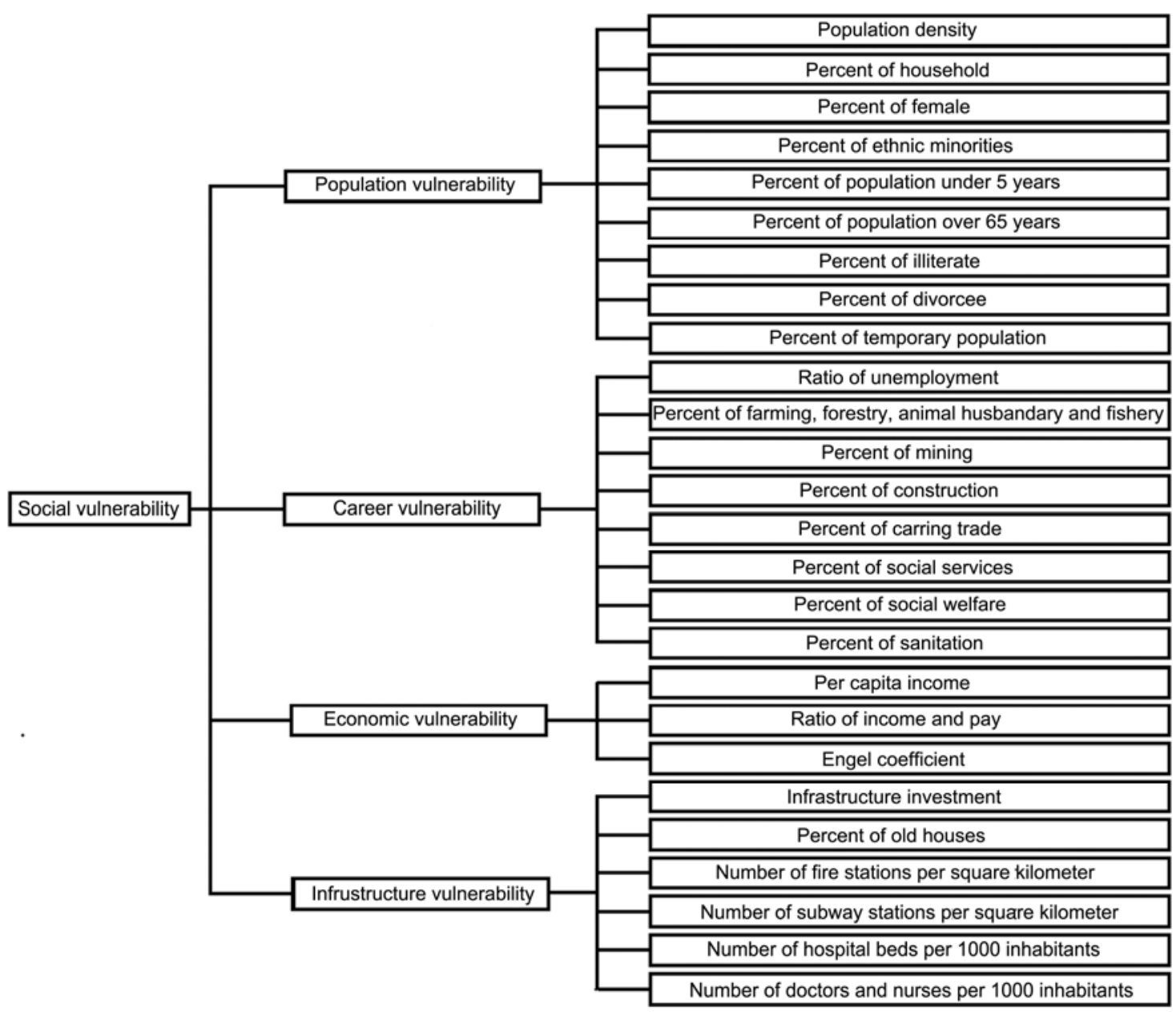

Figure 1 Social vulnerability index system.

Beijing occupies a total area of $16808 \mathrm{~km}^{2}$ covering 18 districts. According to the census of 2000, Beijing had a resident population of 13.6 million inhabitants and a population density of 658 inhabitants $/ \mathrm{km}^{2}$ (the value for urban areas was 27332 inhabitants $/ \mathrm{km}^{2}$ ). In this study, Beijing is divided into 333 areas according to the town and district distributions [21].

As a modern metropolis, Beijing has a normal male-female ratio (from $48 \%$ to $51 \%$ ) and age distribution. However, the vulnerability of Beijing is increasing because of a large transient population and numerous migrant workers. Especially in urban areas, there is high population density, serious traffic jams and many narrow roads called Hutongs built before 1949, which have some negative influence on the city's vulnerability. In rural areas, worse infrastructure, inconvenient traffic and a high percentage of illiterate and ethnic minorities also increase the vulnerability.

\subsection{Data}

The social vulnerability index for Beijing was constructed using the 26 influencing factors based on the characteristics of the metropolis. The data of the 26 influencing factors can be obtained from the census information of Beijing. Because the newest census information (2010) will be published in late 2012, the majority of data used in this study was published in 2000 (for example Haidian district [22], Changping district [23] etc.).

The number of subway stations and fire stations per square kilometer is acquired from the metro route map and fire squadron of Beijing, 2010 respectively (because these two factors have changed greatly in recent years, all data were obtained from the information of 2010). The economic data of the 18 districts were obtained from "Beijing Area Statistical Yearbook" [24].

\section{Methods}

\subsection{Data processing}

Economic, demographic, and infrastructure data are required to analyze social vulnerability. Due to the different units involved, the data are normalized using a Z-score standardization method in this study. Z-score standardiza- 
tion is a standard deviation standardization, and the processed data conforms to a normal distribution.

\subsection{Weight calculation}

The Analytic Hierarchy Process (AHP) method was widely used as a statistic analysis approach to calculate the weight of each influencing factor $[25,26]$. In the traditional AHP method, each influencing factor needs to be subjectively compared by experts. This has the shortcoming that a consistency check cannot be easily satisfied if the number of comparisons is too large. In this study, the vulnerabilities of social, population, career, economic and infrastructure includes four, nine, eight, three and six influencing factors respectively. This means that the expert must make 88 comparisons between each influencing factor. The judging ability of the people is influenced by numerous comparisons. It's very difficult to ensure that each comparison is reasonable and logical due to the large numbers. Since one of the objectives of a consistency check is to ensure that the people who are comparing the factors are rigorous. In this study, we have developed an improved AHP method.

To derive the weight within the index system, an improved AHP method (expert's direct-rating method), which instead of doing a comparison between each factor, was used. This method allows experts to rate the influencing factors between 0.1 and 9 (0.1: the least important factor; 1 : the normal important; 9: the most important factor). Using this method, we can obtain a result through 30 comparisons which means the workload is one third that of the traditional AHP method. This enables experts to improve the efficiency and validity of comparisons, which turns qualitative comparison into quantitative comparison. Through the rating process, the comparison of importance of each influencing factor is easy to calculate.

Using the expert's direct-rating results, the corresponding weight of each level's influencing factor can be calculated based on the traditional AHP process $[27,28]$. The final results of weights including four primary index are obtained and shown in Table 1 The weights of the four primary index are as follows: population vulnerability: 0.4484; career vulnerability: 0.0991; economic vulnerability: 0.1082; infrastructure vulnerability: 0.3443 .

\subsection{Calculating the integrated social vulnerability score}

(i) The classification of influencing factors. After the weight calculation, the population vulnerability, career vulnerability, economic vulnerability, infrastructure vulnerability and integrated social vulnerability will be calculated.

According to the function of influencing factors, 26 influencing factors are classified into two categories, one is negative(+) (the vulnerability will increases when the value of the influencing factor increases), the other is positive(-). It is shown on Table 1.

The influencing factors that increase social vulnerability includes: population density, percent of females, percent of ethnic minorities, percent of population under 5 years, percent

Table 1 Social vulnerability index system and weight distribution

\begin{tabular}{|c|c|c|c|}
\hline Influencing factors & Weights & Influencing factors & Weights \\
\hline Population vulnerability (negative $(+)$, positive $(-)$ ) & 0.4484 & & \\
\hline Population density $(+)$ & 0.0748 & Percent of household (-) & 0.0274 \\
\hline Percent of female $(+)$ & 0.0450 & Percent of ethnic minorities (+) & 0.0310 \\
\hline Percent of population under 5 years $(+)$ & 0.0684 & Percent of population over 65 years $(+)$ & 0.0730 \\
\hline Percent of illiterate $(+)$ & 0.0491 & Percent of divorcee $(+)$ & 0.0384 \\
\hline Percent of temporary population $(+)$ & 0.0413 & & \\
\hline Career vulnerability & 0.0991 & & \\
\hline Ratio of unemployment $(+)$ & 0.0198 & Percent of primary industry $(+)$ & 0.0090 \\
\hline Percent of mining $(+)$ & 0.0107 & Percent of construction $(+)$ & 0.0130 \\
\hline Percent of carrying trade $(+)$ & 0.0097 & Percent of social services $(-)$ & 0.0099 \\
\hline Percent of social welfare $(-)$ & 0.0094 & Percent of sanitation $(-)$ & 0.0176 \\
\hline Economic vulnerability & 0.1082 & & \\
\hline Per capita income $(-)$ & 0.0469 & Ratio of income and pay (-) & 0.0495 \\
\hline Engel coefficient $(+)$ & 0.0288 & & \\
\hline Infrastructure vulnerability & 0.3443 & & \\
\hline Percent of old houses $(+)$ & 0.0380 & Number of fire stations per square kilometer (-) & 0.0654 \\
\hline Number of subway stations per square kilometer $(-)$ & 0.0417 & Number of hospital beds per 1000 inhabitants (-) & 0.0730 \\
\hline Number of doctors and nurses per 1000 inhabitants (-) & 0.0767 & Infrastructure investment (-) & 0.0495 \\
\hline
\end{tabular}


of population over 65 years, percent of illiterate people, percent of divorcees, percent of temporary population, rate of unemployment, percent of farming, forestry, animal husbandry and fisheries, percent of mining, percent of construction, percent of carrying trade, Engel coefficient and percent of old houses. Other influencing factors will decrease the social vulnerability.

Because the two functions play a contrary part in vulnerability, the data's polarity must be transformed. Thus, all influencing factors will have the same correlation with vulnerability.

(ii) Calculating the vulnerability scores. After all data is normalized using the Z-score method, the data for the influencing factors which increase the vulnerability should be multiplied by -1.0 . Through normalization and polarity transformation 26 final data points will be obtained. In this study, the linear weighted integrated function method to calculate the SOVI because the index are independent each other based on correlative analysis. The formula [12] is below:

$$
\mathrm{SOVI}=\sum_{i=1}^{26}\left(w_{i} \cdot x_{i}\right)
$$

where SOVI is a relative value in this method and can be used to compare the vulnerability between different areas, $i$ $(1,2, \ldots, 26)$ is the sequence number of influencing factors, $w_{i}$ is the weight of each influencing factor, $x_{i}$ is the processed final normalized data of each area.
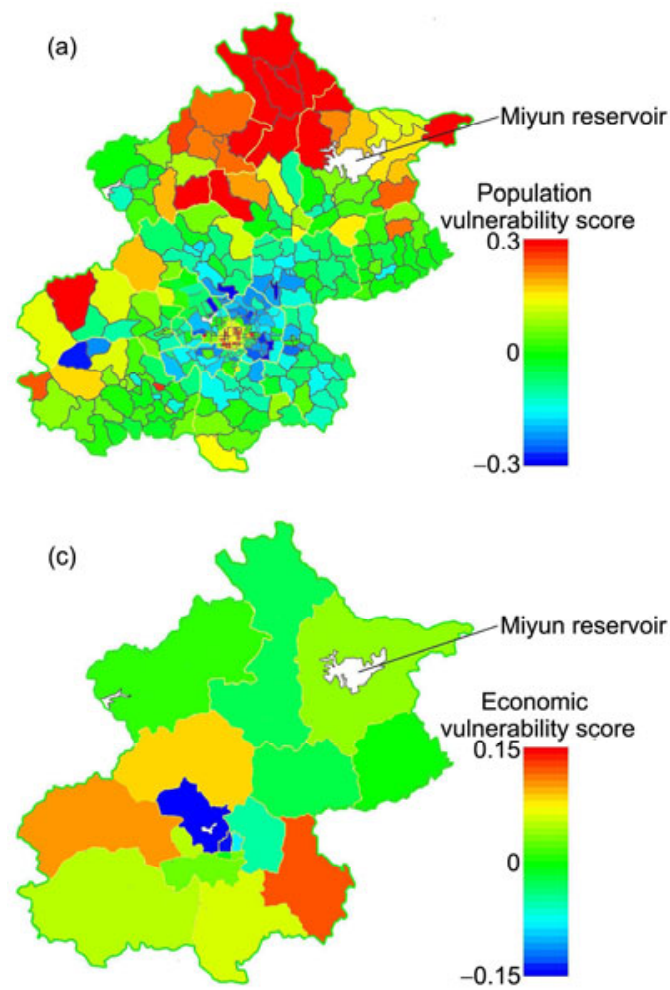

The SOVI of integrated social vulnerability is the summation of the SOVI of population vulnerability, career vulnerability, economic vulnerability and infrastructure vulnerability according to the weight of each factor.

\section{Results}

\subsection{The spatial distribution of Beijing's social vulnerability}

The spatial distributions of Beijing's population vulnerability, career vulnerability, economic vulnerability and infrastructure vulnerability are shown in Figure 2. Figure 3 shows the integrated social vulnerability. Blue indicates the lowest vulnerability and red indicates the highest vulnerability, with the intermediate stages being shown in the gradual shading from blue to red.

From Figure 3, it can easily be seen that the vulnerability of rural areas is higher than that of central urban areas. North Beijing in particular has the highest social vulnerability scores. Moderate vulnerability is found in suburban areas, whereas the lowest vulnerability is obtained in central urban areas.

Considering the characteristics of Beijing, the central urban areas with large number of population is very important. Therefore, the distribution map of social vulnerability score for the central urban areas of Beijing is drawn in Figure 4 and detailed information is shown clearly. The mapping of
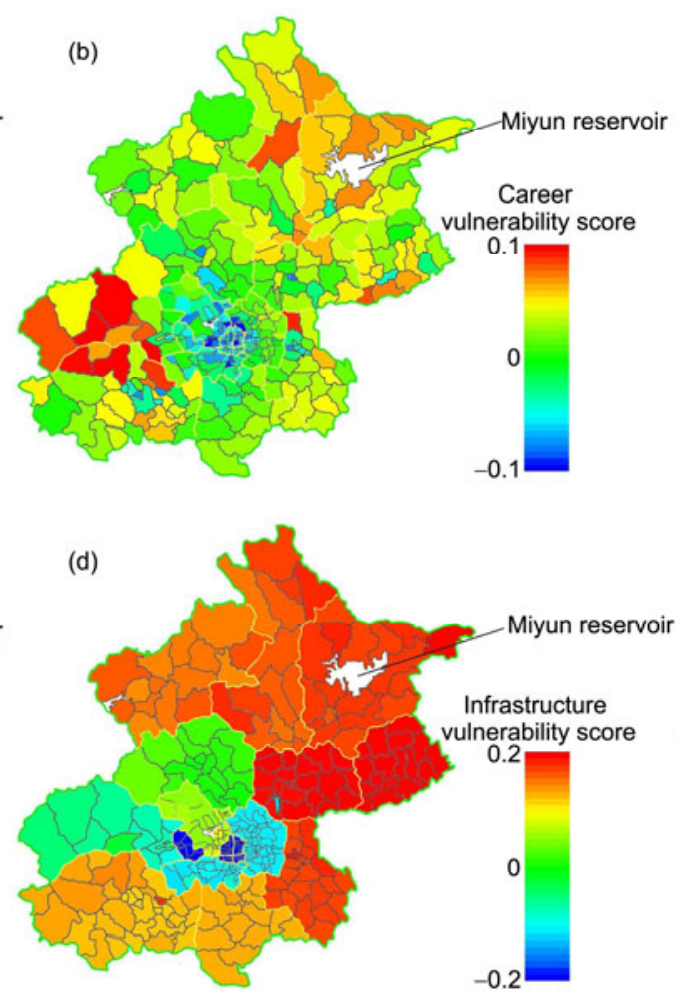

Figure 2 The spatial distribution sketch of different vulnerability scores for Beijing. (a) Population vulneratility; (b) career vulnerability; (c) economic vulnerability; (d) infrastructure vulnerability. 


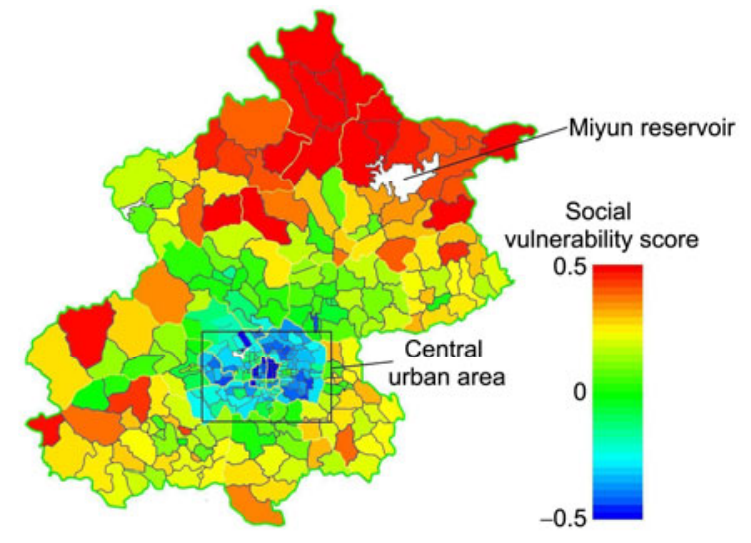

Figure 3 The spatial distribution sketch of social vulnerability score of Beijing.

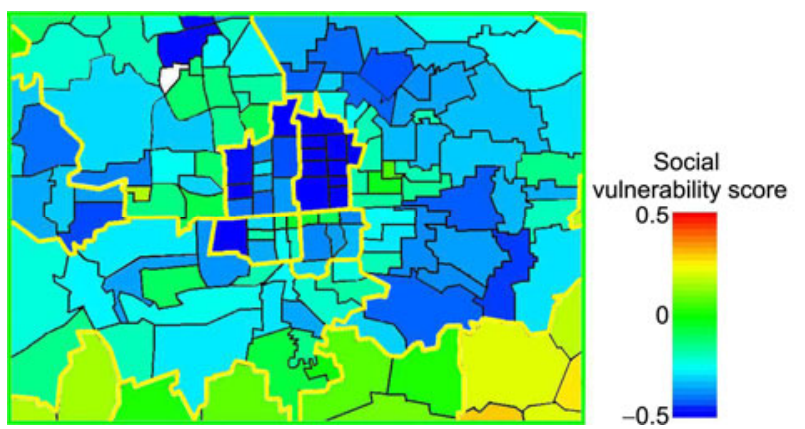

Figure 4 Distribution sketch of social vulnerability score for the central urban areas of Beijing.

these all data shows geographic pattern of social vulnerability to disaster that can be used in prevention, reduction and recover of disaster.

\subsection{Sensitivity analysis}

Sensitivity analysis for each influencing factor was performed, which plays an important role in vulnerability analysis $[29,30]$. The process is as follows:

(i) Firstly, the target influencing factor's weight is multiplied by a coefficient which should be larger than 1.0. The coefficient in this case is set to be 5.0 (any value is okay, the selection of 5.0 is just for convenient treatment). Thus, the target influencing factor's weight is multiplied by 5.0 in the condition that the other influencing factors' relative weights are constant.

(ii) To assure that the proportion of the other 25 influencing factors' weights are constant, we adjust the other 25 influencing factors' weights and let the sum of these 26 influencing factors' weights equal 1.0. The equation is: $X_{n p}=\frac{X_{m p} \cdot\left(1-\mathrm{C} \cdot X_{m q}\right)}{\left(1-X_{m q}\right)}, p, q \in[1,26], p$ and $q$ are integers, where $X_{n p}$ is the new influencing factor's weight of one of the 25 influencing factors after calculating, $X_{m p}$ is the original weight of one of the 25 influencing factors, $X_{m q}$ is the original weight of the target influencing factor, $C$ is the coefficient (in this study, 5.0 is used).

(iii) The new SOVI $\left(\mathrm{SOVI}_{\text {new }}\right)$ can be obtained by eq. (1) using the new influencing factor's weights. Then the sensitivity score (SENS) is

$$
\mathrm{SENS}=\mathrm{SOVI}_{\text {new }}-\mathrm{SOVI}_{\text {old }} \text {, }
$$

where $\mathrm{SOVI}_{\text {old }}$ is the SOVI value before sensitivity analysis. The higher the sensitivity score, the greater the influence of this target influencing factor.

Then, the 26 new influencing factors' weights were calculated, and a $26 \times 26$ data array was obtained. The maximum sensitivity score of the 26 factors of each area can be found and this influencing factor is the most disadvantageous of all factors. The vulnerability level [31] can be improved efficiently by improving this influencing factor.

Due to the large number of data, only five areas that have high sensitivity scores are shown in Figure 5 as an example. At the same time, only five influencing factors are shown in the analysis because these factors have the highest weight and sensitivity scores. Figure 5 reflects the sensitivities of influencing factors for each area, and it is easy to get the characteristics of changes in sensitivity. To explore the sensitivity of each area, we can then understand how to improve an area's vulnerability level through this sensitivity analysis, which in turn can be used in planning development for Beijing. Taking Yongding street for example (Figure 5), we can easily understand that the highest sensitivity scores of these five factors is about 2.0 and then we can obtain the most sensible factor which is population density. Thus for Yongding street, population density is the most disadvantageous factor, and should be the first factor addressed. It also shows that the percentage of households has the lowest sensitivity score in Liyuan street and thus improvement of this factor is not urgent.

The scores for all areas were obtained and an integral sensitivity distribution map is shown in Figure 6. It is shown that sensitivity score at the suburban areas seem fairly low, while high sensitivity score areas composed of central and rural areas. The results can provide disaster management of each area and contribute to decrease the social vulnerability before, during and after a disaster.

\section{Discussion}

In this study, taking Beijing as an example, the social vulnerability index system was established and an improved Analytic Hierarchy Process method was developed to assess social vulnerability. The distribution of the social vulnerability of Beijing is obtained and improved directions for the development of each area are provided. We divided the 


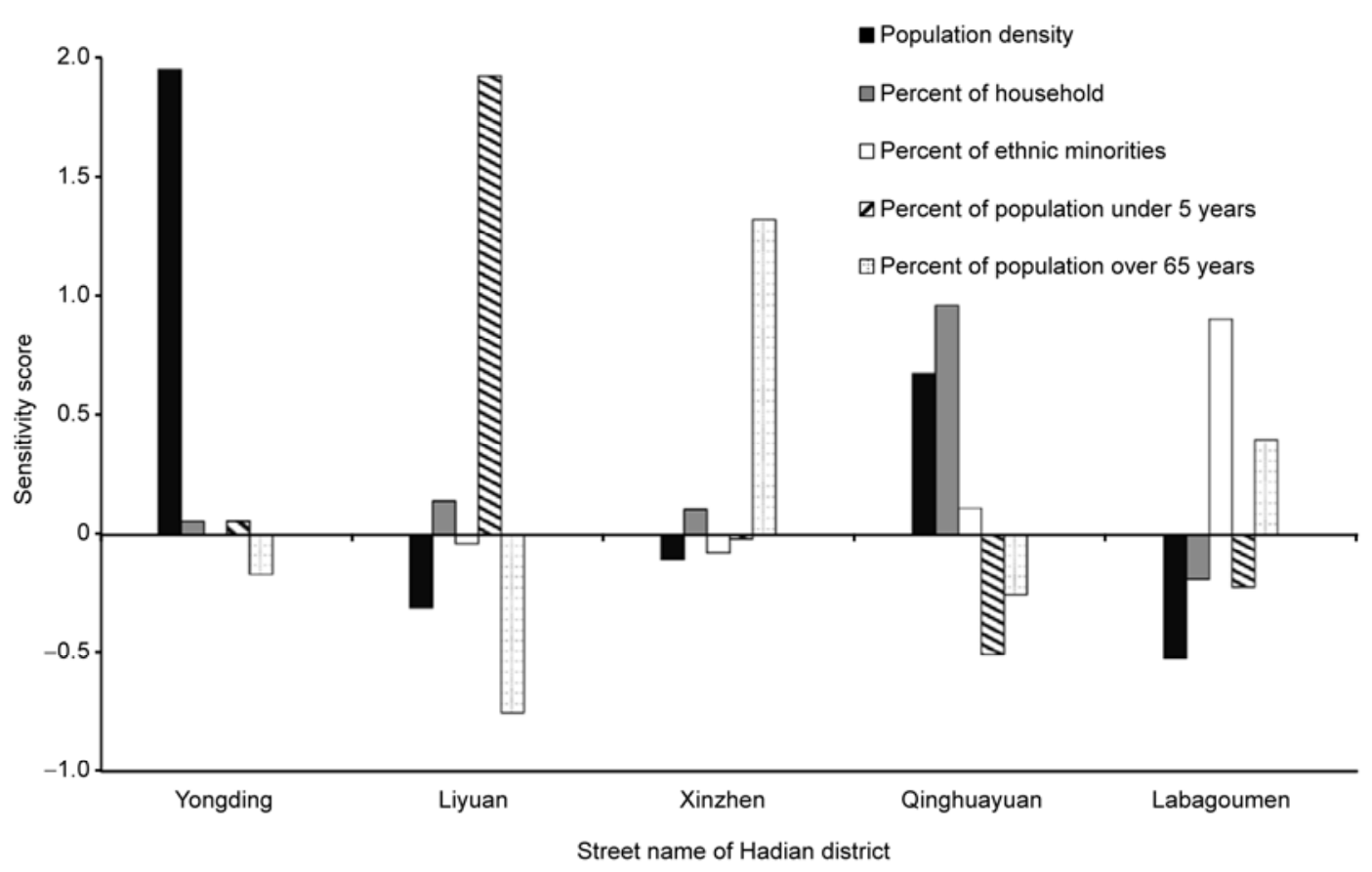

Figure 5 Sensitivity scores of five typical areas.

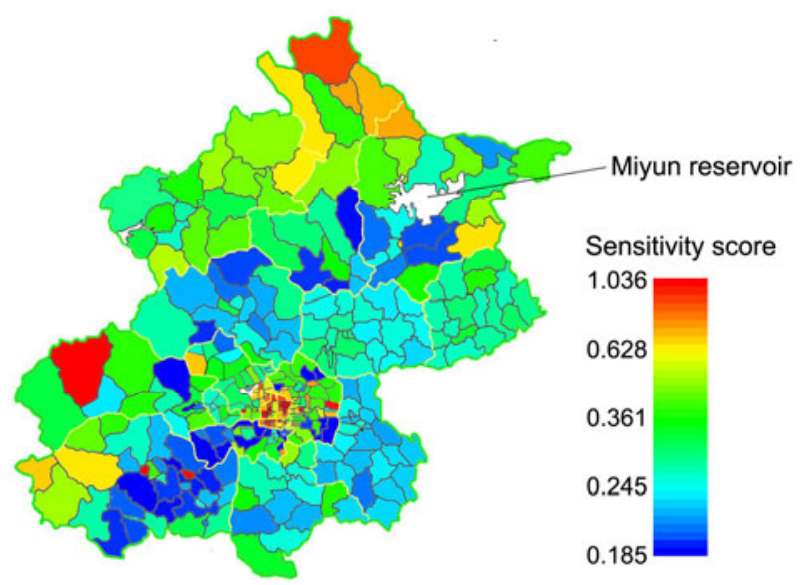

Figure 6 Distribution sketch of sensitivity score.

whole area into three parts including rural, central urban and suburban areas. The distribution map of social vulnerability of Beijing shows that the SOVI is very high in north Beijing. For these areas, the high social vulnerability is a consequence of population vulnerability, career vulnerability and higher infrastructure vulnerability. Within these areas, roughly the high percentage of illiterate people, children, temporary population (the lower housing price attracts more migrant workers) and extremely high percentage of the elderly all lead to the high population vulnerability there. The weight of percent of unemployment is the most important contributor to career vulnerability. In these areas, a high percentage of unemployment and high-risk careers (mining, construction, carrying trade etc.) are the most important reason for high career vulnerability. As for infrastructure vulnerability, the development of subway stations, fire stations, hospitals and so on in these areas is far lower than in central urban areas. Also, there are many old dilapidated houses that are too dangerous to live in. Through the sensitivity analysis and for the above-mentioned reasons, we should find that the direction to reduce the vulnerability of these areas to decrease social vulnerability.

On the other hand, it is found that central urban areas have low social vulnerability. However, the population vulnerability of these areas is high although there is lower percentage of ethnic minorities and illiterate people and a normal percentage of females, children and the elderly, because there are too many people living there (population density: about $23000 / \mathrm{km}^{2}$ ). Population vulnerability plays an important role when a disaster strikes. Therefore, in these areas, the population vulnerability must be addressed when making disaster prevention plan. From another point of view, the better career distribution, better economic and infrastructure conditions lead to lower vulnerabilities of career, economic and infrastructure. Also, it is easy seen that central urban areas have low vulnerability score but have high sensitivity score. This result shows that we should focus on the disaster prevention of central urban areas although the low vulnerability. In suburban areas the level of social vulnerability is medium. The social factors of the areas between the rural and central urban areas should be improved in balance to decrease the social vulnerability.

According to the analysis above, social vulnerability can be improved in different factors. Through this study, we can provide development plans for each area, and act according 
to circumstances. Combining with the sensitivity analysis, we can determine the questions to be asked. And in answering these questions, the vulnerability can be greatly decreased. Without a doubt, this method could be used to analyze the vulnerability of other metropolises.

The next phase of this research will be to study the social vulnerability over time which will enable us to understand the dynamic evolution mechanism of social vulnerability. The results will help us adjust development plans so as to decrease vulnerability and enhance resilience.

This work was supported by the National Natural Science Foundation of China (71173128) and Ministry of Science and Technology of China (2011BAK07B02).

1 Cutter S L, Mitchell J T, Scott M S. Revealing the vulnerability of people and places: A case study of Georgetown county, south Carolina. Ann Assoc Am Geogr, 2000, 90: 713-437

2 Gladwin H, Lazo J K, Morrow B H, et al. Social science research needs for the hurricane forecast and warning system. Nat Hazards Rev, 2007, 3: 87-95

3 Phillips B D, Morrow B H. Social science research needs: Focus on vulnerable populations, forecasting, and warnings. Nat Hazards Rev, 2007, 8: 61-68

4 Schmidtlein M C, Deutsch R C, Piegorsch W W, et al. A sensitivity analysis of the social vulnerability index. Risk Anal, 2008, 28: 10991114

5 Cutter S L, Boruff B J, Shirley W L. Social vulnerability to environmental hazards. Soc Sci Q, 2003, 84: 242-261

6 Burton C G. Social vulnerability and hurricane impact modeling. Risk Anal, 2008, 4: 58-68

7 Jose M O M. Social vulnerability indexes as planning tools: Beyond the preparedness paradigm. Risk Res, 2009, 12: 43-58

8 Flanagan B E, Gregory E W, Hallisey E J, et al. A social vulnerability index for disaster management. Emerg Manag, 2011, 1: 1-22

9 Adger W N. Social vulnerability to climate change and extremes in coastal Vietnam. World Dev, 1999, 27: 249-269

10 Fekete A. Validation of a social vulnerability index in context to river-floods in Germany. Nat Hazard Earth Sys, 2009, 9: 393-403

11 Shi P J, Wang J A, Zhou J H, et al. Integrated risk management of flood disaster in China: To balance flood disaster magnitude and vulnerability in metropolitan regions. J Nat Disaster, 2004, 8: 1-7

12 Ge Y. The Research of analysis of social vulnerability for flood hazard: A case study of Changsha, Hunan (in Chinese). Doctoral Disseration. Beijing: Beijing Normal University, 2006

13 Zhang H Q, Ma X Q, Chen X Y, et al. Analysis on vulnerability of winter wheat in Anhui Province based on GIS. Chin Agr Sci Bull, 2011, 27: 146-151

14 Wu S H, Dai E F, Huang M, et al. Ecosystem vulnerability research of climate change in 21st in China. Chin Sci Bull, 2007, 52: 811-817

15 Brooks N. Vulnerability, risk and adaption: A conceptual framework. Tyndall Cent Clim Chang Res, Working Paper 38

16 IPCC. Impacts, Adaptation and Vulnerability, Summary for Policymakers, WMO. Clim Chang, 2001

17 Turner B L. Vulnerability and resilience: Coalescing or paralleling approaches for sustainability science? Global Environ Chang, 2010: 570-576

18 Chakraborty J, Tobin G A, Montz B E. Population evacuation: Assessing spatial variability in geophysical risk and social vulnerability to natural hazards. Nat Hazards Rev, 2005, 1: 23-33

19 Fazey I, Kesby M, Evely A, et al. A three-tiered approach to participatory vulnerability assessment in the Solomon Islands. Global Environ Chang, 2010, 20: 713-728

20 Lazo J K, Waldman D M, Morrow B H, et al. Household evacuation decision making and the benefits of improved hurricane forecasting: Developing a framework for assessment. Weather Forecast, 2010, 1: 207-219

21 Beijing Municipal Bureau of Civil Affairs. The Manual of Administrative Division of Beijing (in Chinese). Beijing: Tongxin Book Press of Beijing, 1994

22 Liang Y. Census information of Haidian district of Beijing, 2000. The 5 th census information office and statistical bureau of Haidian district, 2002

23 Liu F L. Census information of Changping district of Beijing, 2000. The 5th census information office and statistical bureau of Changping district, 2002

24 Beijing Statistics Bureau, Beijing Survey Corps of National Statistics Bureau. Beijing Area Statistical Yearbook (in Chinese). Beijing: Tongxin Publisher, 2008

25 Guo J Y, Zhang Z B, Sun Q Y. Applications of AHP method in safety science. J Safety Sci Tech, 2008, 2: 69-73

26 Zhang Y L. Study on relative people vulnerability of city emergencies. J Catastrophology, 2010, 3: 90-95

27 Xu X P, Zhang L B, Duan L Z, et al. Research on reciprocating compressors safety assessment system based on AHP. Ind Safety Environ Prot, 2012, 1: 27-30

28 Shi L, Zhang R F, Xie Q Y, et al. AHP implication of fire risk analysis in the public buildings. Chin Sci Bull, 2009, 54: 329-336

29 Cui S H, Li F Y, Huang J, et al. Review of sensitivity research on the context of global change. Adv Earth Sci, 2009, 9: 1033-1041

30 She J Y, Zhou D H, Liu Z C, et al. Ecological sensitivity analysis on Wanquan River Watershed Based on GIS. Chin Agr Sci Bull, 2012, 28: 69-73

31 Pan F, Tian C Y, Shao F, et al. Evaluation of ecological sensitivity in Karamay, Xinjiang, Northwest China. Acta Geograph Sin, 2011,11: 1497-1507

Open Access This article is distributed under the terms of the Creative Commons Attribution License which permits any use, distribution, and reproduction in any medium, provided the original author(s) and source are credited. 